\title{
Effect of a Chronic Obstructive Pulmonary Disease (COPD) Intervention on COPD Awareness in a Regional City in Japan
}

\author{
Masaharu Asai ${ }^{1,2}$, Takako Tanaka ${ }^{1}$, Ryo Kozu ${ }^{3}$, Chika Kitagawa ${ }^{4}$, \\ Mitsuru Tabusadani ${ }^{5}$ and Hideaki Senjyu ${ }^{1}$
}

\begin{abstract}
Objective The purpose of this study was to examine the effect of an intervention for chronic obstructive pulmonary disease (COPD) on COPD awareness in a regional city in Japan.

Methods Self-administered questionnaires were completed by the residents of the city of Matsuura, Japan. Residents ( $\geq 50$ years) of the mainland in Matsuura were included in a COPD intervention project (mainland group), while residents of the islands district received no intervention due to geographical issues (island group). The rates of COPD awareness and accuracy of responses to the questions about COPD were compared between the two groups.

Materials The study included 5,891 residents 40 to 74 years of age of Matsuura in 2013. The mainland group comprised 4,419 subjects, and the island group 1,472 included subjects.

Results The overall response rate to the questionnaire was $24.6 \%$, with similar response rates between the two groups. The rate of COPD awareness in the mainland group was $24.5 \%$, which was significantly higher than that observed in the island group $(11.8 \%)(\mathrm{p}<0.01)$. The rate of awareness tended to decrease in association with increasing age. Among 276 responders who stated they were aware of COPD, the accuracy rate for responses to the questions about COPD was not significantly different between the groups.

Conclusion In the present study, there was a difference in COPD awareness between the two groups, suggesting that COPD interventions may increase awareness of the disease. However, the level of knowledge regarding COPD remained low and modifications to the intervention are required to improve awareness of the condition, especially among elderly subjects.
\end{abstract}

Key words: chronic obstructive pulmonary disease (COPD), awareness, intervention, elderly, Japanese

(Intern Med 54: 163-169, 2015)

(DOI: 10.2169/internalmedicine.54.2916)

\section{Introduction}

Chronic obstructive pulmonary disease (COPD) occurs as a result of long-term exposure to cigarette smoke and other forms of atmospheric pollution (1). The prevalence and mortality rate of COPD are increasing. As of 2012, COPD was the ninth most common cause of death in Japan, and the disease is predicted to become the third most common disease-related cause of death in the world by 2020 (2-4). Although the number of patients with COPD in Japan receiving treatment is approximately 260,000 (2012 data) (5), the Nippon COPD Epidemiology Study reported that the number of potential patients is much greater, at $8.6 \%$ of the population 40 years of age or older, or approximately $5,300,000$ Japanese subjects (6). In a global epidemiological

${ }^{1}$ Department of Cardiopulmonary Rehabilitation Science, Nagasaki University Graduate School of Biomedical Sciences, Japan, ${ }^{2}$ Department of Rehabilitation Medicine, Tagami Hospital, Japan, ${ }^{3}$ Department of Rehabilitation Medicine, Nagasaki University Hospital, Japan, ${ }^{4}$ Department of Rehabilitation Medicine, Nagasaki Respiratory Rehabilitation Clinic, Japan and ${ }^{5}$ Center for Industry, University and Government Cooperation, Nagasaki University, Japan

Received for publication March 19, 2014; Accepted for publication June 8, 2014

Correspondence to Dr. Hideaki Senjyu, senjyu@ nagasaki-u.ac.jp 
Table 1. Population of the Mainland and Island Groups in Matsuura City Aged 40 to 74 Years Old, and the Number of Subjects Attending for a Health Checkup

\begin{tabular}{llrrrrr}
\hline $\begin{array}{l}\text { Age } \\
\text { years }\end{array}$ & & \multicolumn{2}{c}{ Population } & & & \multicolumn{2}{c}{ Subjects having a health checkup } \\
\cline { 6 - 7 } & & Mainland & Island & & Mainland & Island \\
\hline $40-49$ & $\mathrm{n}$ & 2,084 & 442 & & 549 & 167 \\
$50-59$ & $\mathrm{n}$ & 2,727 & 716 & & 884 & 333 \\
$60-69$ & $\mathrm{n}$ & 3,071 & 827 & & 1,911 & 606 \\
$70-74$ & $\mathrm{n}$ & 1,187 & 385 & & 1,075 & 366 \\
Total & $\mathrm{n}$ & 9,069 & 2,370 & & 4,419 & 1,472 \\
\hline
\end{tabular}

study, the number of potential individuals with COPD was reported to be $7.8-19.7 \%$ of the population, with an increasing prevalence in association with increasing cigarette consumption and age (7-9).

It is possible to prevent the progression of COPD with early diagnosis and effective treatment (1,9-11). Smoking cessation is the most effective means of preventing COPD (1), and it is important to educate smokers as well as other members of the general public, as both passive smoking and air pollution are risk factors for COPD (1). Symptoms occurring early in the disease trajectory, specifically breathlessness on exertion, are often overlooked by the individual and attributed to the normal aging process or thought to be the result of being unfit. For this reason, people with early signs of COPD often fail to seek medical attention and thus do not receive appropriate treatment in the early stages of the disease (10-13). Furthermore, although cigarette packages carry warnings of the risk of lung cancer and COPD, data suggest that COPD awareness is lower among people with a history of smoking, particularly current smokers, compared with non-smokers $(14,15)$. Failure to recognize the early symptoms of COPD precludes potential early treatment with improved outcomes.

Several studies of COPD awareness have been conducted in Japan and elsewhere. For example, the Japan GOLD Committee carried out an online questionnaire survey among 10,000 individuals, with 2,000 participants in each decade of life from 20 to 60 years of age or older. The proportion of respondents who had knowledge about "COPD" or who had heard the term "COPD" was $9.1 \%$ and $21.4 \%$, respectively (16). In another study in Japan of 335 subjects 18 years of age or older who had visited a community hospital, the proportion of respondents with knowledge about COPD or who had heard the term 'COPD' was 9.3\% and $17.6 \%$, respectively (14). Taken together, the results of these studies demonstrate that awareness of COPD within Japan is low. In 2012, the Ministry of Health, Labour and Welfare established the objective of improving COPD awareness with the aim of promoting early detection and early treatment at the "Health Japan 21 (2nd series)" conference. The goal of this initiative was to raise the rate of COPD awareness to $80 \%$ within the next 10 years (17).

Since 2004 , we have worked to establish a medical information sharing system for the early detection and treatment of COPD and to raise awareness of COPD in cooperation with health care centers, the government and medical associations in Matsuura District, Nagasaki prefecture. We implemented a COPD intervention that included COPD checkups for residents 50 years of age or older, with reinforcements of public health messages related to health and smoking cessation and articles about COPD treatment and methods of pulmonary rehabilitation in local publications. Few published studies have reported the results of COPD awareness interventions. The aim of this study was therefore to investigate the effects of a COPD intervention by comparing data for COPD awareness among the residents in two areas with the same medical and administrative services, while the residents of only the mainland area were included in a COPD project due to geographical constraints.

\section{Materials and Methods}

\section{Subjects}

This cross-sectional study was performed in the city of Matsuura in the north of Nagasaki prefecture. The city comprises a mainland area and five islands, with a population of 24,580 in 2013. The residents of the mainland and the islands have the same local government and receive the same medical and administrative services. Table 1 presents the population data for residents 40-74 years of age on the mainland and two islands (Takashima and Fukushima islands) and the number of subjects attending a local clinic for health checkups. The sample comprised a total of 5,891 residents, including 4,419 residents of the mainland district of Matsuura, where the COPD intervention project was implemented, and 1,472 residents of the island district, who were unable to participate in the COPD project due to geographical reasons.

\section{Methods: COPD intervention}

We established the COPD Task Force in 2004 in cooperation with the Nagasaki Prefectural Kenhoku Health Center, Matsuura City, Kita Matsuura Medical Association and Hirado Medical Association with the objectives of enabling local residents to properly understand COPD and implement preventive measures, such as smoking cessation. Through this Task Force, using municipal publications targeting all residents of Matsuura city, we explained the concept of "COPD" and advertised public lectures about the disease. In addition, we organized and held COPD checkups for the purpose of early detection for residents of the mainland. The COPD checkups were conducted in 2006 and 2012. For persons identified with potential COPD during the COPD medical checkups, we requested specialists to provide a definitive diagnosis. Spirometry was required to establish a diagnosis of COPD, and a post-bronchodilator the forced expiratory volume in 1 second $\left(\mathrm{FEV}_{1}\right)$ /forced vital capacity ratio (FVC) of $<0.70$ was used to confirm the presence of persistent airflow limitation (1). For persons diagnosed with COPD, we implemented annual checkups focusing on the 


\begin{tabular}{|c|c|c|c|c|}
\hline & 2004 & 006 & 2011 & 2013 \\
\hline \multirow{3}{*}{$\begin{array}{l}\text { Understanding } \\
\text { current status }\end{array}$} & \multicolumn{4}{|c|}{ Establishment of COPD Task Force } \\
\hline & \multirow{2}{*}{\multicolumn{2}{|c|}{ COPD checkups }} & \multirow{2}{*}{\multicolumn{2}{|c|}{ COPD checkups }} \\
\hline & & & & \\
\hline \multirow{3}{*}{$\begin{array}{l}\text { Health } \\
\text { management for } \\
\text { residents }\end{array}$} & & \multicolumn{3}{|l|}{ Follow-up checkups(\#): Once per year } \\
\hline & & \multicolumn{3}{|c|}{ COPD classes $(\#)($ Smoking cessation classes, Health classes): Four times per year } \\
\hline & & \multicolumn{3}{|l|}{ Patient meetings(\#): Twice per year } \\
\hline $\begin{array}{l}\text { Establishment of } \\
\text { medical systems }\end{array}$ & & $\begin{array}{l}\text { Preparation and displaying of medical posters } \\
\text { (COPD diagnosis, treatment, respiratory rehabilitation) }\end{array}$ & & \\
\hline Staff education & & \multicolumn{3}{|c|}{$\begin{array}{l}\text { Hosting of training workshops } \\
\text { (guidance on methods for respiratory examinations, respiratory rehabilitation): Once per year each }\end{array}$} \\
\hline \multirow{3}{*}{$\begin{array}{l}\text { Awareness and } \\
\text { education }\end{array}$} & \multicolumn{4}{|c|}{ Lectures and publications $(*)$ (ongoing series); Open lectures for city residents*: Once per year } \\
\hline & & \multicolumn{3}{|c|}{ Explanation of the results of COPD checkup to residents and medical stuff: Once per year } \\
\hline & & \multicolumn{3}{|l|}{ Preparation of pamphlets on rehabilitation } \\
\hline
\end{tabular}

(\#) Follow-up checkups, COPD classes and patient meetings were conducted for persons with a definitive diagnosis of COPD and residents with potential COPD.

$\left(^{*}\right)$ City publications were distributed to all households in Matsuura city and open lectures for city residents were publicized among all residents in Matsuura city, both of which could be viewed and/or attended

Figure 1. Overview of the educational chronic obstructive pulmonary disease (COPD) awareness activities.

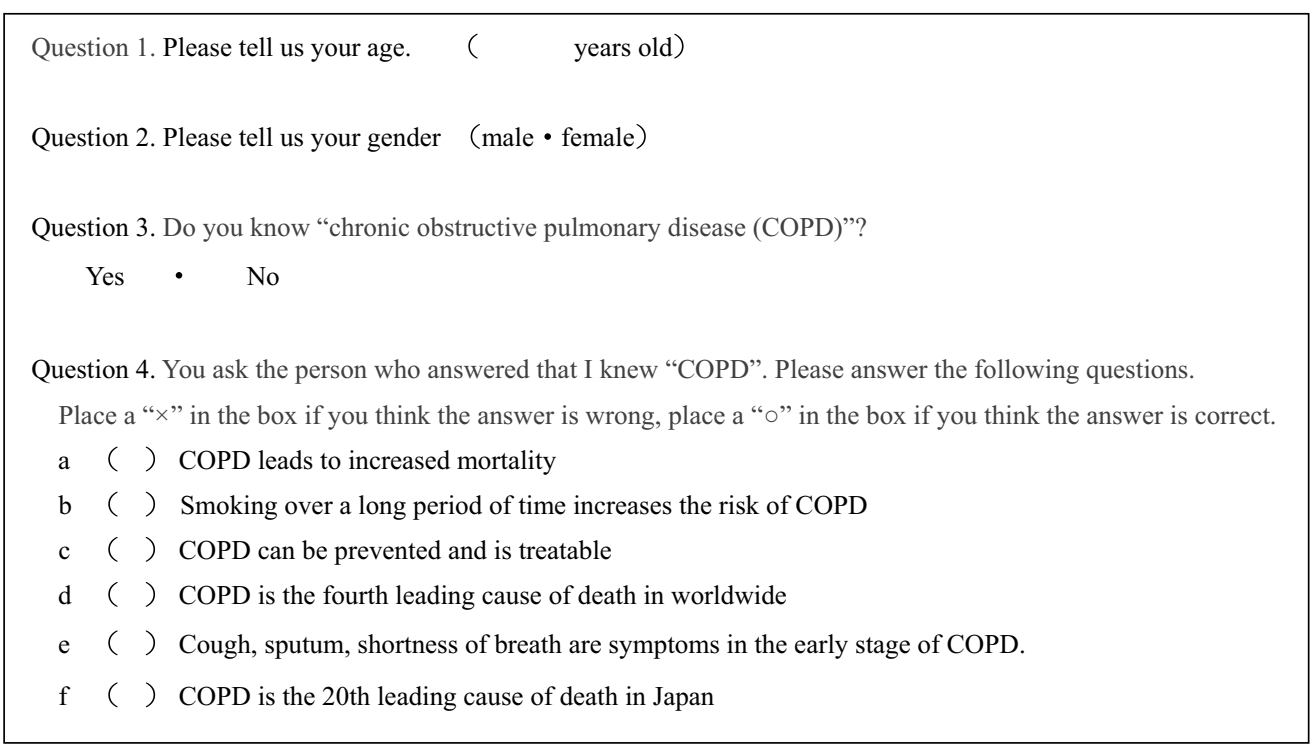

Figure 2. COPD awareness questionnaire.

respiratory function, including spirometry. We also held smoking cessation and health education classes, with guidance on pulmonary rehabilitation (exercise training, upper/ lower limb exercises, breathing control) for residents with a definitive diagnosis of COPD and their families.

Approximately 300 residents participated in the COPD checkups in both 2006 and 2012. The annual checkups for persons diagnosed with COPD included approximately 50 residents annually. Approximately 100 residents attended public lectures on the treatment of COPD and methods for respiratory rehabilitation, and approximately 20 residents participated in smoking cessation and health education classes. All participants of these events were residents of the mainland of Matsuura city. In addition, approximately 50 medical staff attended professional study meetings. An overview of the COPD educational activities is shown in Fig. 1.

\section{Questionnaire}

In the first part of the study, a self-administered questionnaire (Fig. 2) was first posted to all residents of the mainland and two islands (Takashima and Fukushima islands) 40 to 74 years of age who were scheduled to have a health checkup, then collected at the checkup sites. Based on the questionnaire responses, the level of awareness of COPD was determined and compared between the group of residents of the mainland district where the COPD intervention had been implemented (mainland group) and the residents of the island regions who did not participate in the COPD pro- 
Study 1.

Individuals aged between 40 to 74 years old and resided in Matsuura city

Total 11,439 (Mainland group: $\mathrm{n}=9,069$, Island group: $\mathrm{n}=2,370$ )

Subjects who were targets for a health checkup in Matsuura city

Total 5,891 (Mainland group: $\mathrm{n}=4,419$, Island group: $\mathrm{n}=1,472$ )

$\downarrow$

Subjects who answered COPD awareness questionnaire

Total 1,447 (Mainland group: $\mathrm{n}=1,078$, Island group: $\mathrm{n}=369$ )

$\downarrow \quad$ Missing data (No response for age and/or gender): $n=41$

Available data

Total 1,406 (Mainland group: $\mathrm{n}=1,051$, Island group: $\mathrm{n}=355$ )

Study2.

Subjects that answered the questionnaire on COPD

$\mathrm{n}=1,406$

$\downarrow$

Total 299 (Mainland group: $\mathrm{n}=257$, Island group: $\mathrm{n}=42$ )

$\downarrow \rightarrow$ Missing data (Subjects who did not answer any questions: $n=23$ )

Number of subjects whose data were used to calcuate response and accuracy rates

Total 276 (Mainland group: $\mathrm{n}=239$, Island group: $\mathrm{n}=37$ )

Figure 3. Study flow.

ject (island group).

In the second part of the study, respondents who stated that they were aware of COPD completed a second questionnaire, which consisted of six questions related to knowledge about the condition. Each question was based on information included in COPD pamphlets distributed to the medical institutions. The responses to the questionnaire were treated as valid if at least one of the six questions had been answered. Using all valid questionnaires, we calculated the total response rate and accuracy rates for each question. The response rate was calculated as the (total number of responses - number of missing responses)/total number of responses) $\times 100$, and the accuracy rate was calculated as the (number of correct responses/(total number of valid data number of missing responses)) $\times 100$.

\section{Statistical analysis}

A comparison of data between the mainland and island groups was performed using the Mann-Whitney $U$ test and Chi-square test. The significance level was set at 5\%. All analyses were performed using the statistical software program IBM SPSS ver. 18 for Windows (IBM SPSS, Tokyo, Japan).

\section{Results}

An overview of the study participants is given in Fig. 3 . Of a total of 5,891 subjects sent a questionnaire, we received responses from 1,447 participants, yielding an overall response rate of $24.6 \%$ [23.8\% $(n=1,078)$ in the mainland group and $25.1 \%(n=369)$ in the island group; this difference was not significant, $\mathrm{p}=0.63$ ]. Data for 41 subjects were not included in the analyses as these individuals failed to record their age and/or sex. Therefore, the study sample comprised 1,406 subjects. The characteristics of the subjects are
Table 2. Characteristics of the Subjects who Responded to the COPD Awareness Survey

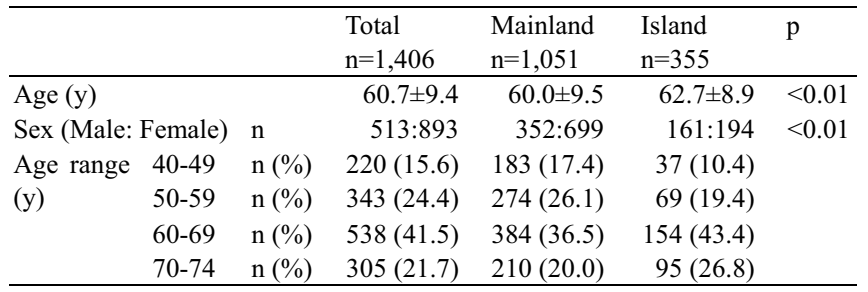

Age presented as mean \pm standard deviation.

shown in Table 2. The island group comprised a similar number of men and women; however, there were more women in the mainland group $(\mathrm{p}<0.01)$. Subjects 60 to 74 years of age represented $63.2 \%$ of the total population, and the mean age of the island group was higher than that of the mainland group (62.7 vs. 60.0 years; $\mathrm{p}<0.01$ ).

The overall number of respondents who stated that they were aware of COPD was 299 (21.3\%), including 257 $(24.5 \%)$ subjects in the mainland group and 42 (11.8\%) subjects in the island group (Table 3), with a significantly higher rate in the mainland group $(\mathrm{p}<0.01)$. The rate of COPD awareness among the subjects 70-74 years of age was low in both groups, and there were significant differences in the rates among the subjects 50-59 ( $\mathrm{p}=0.001)$ and 60-69 ( $\mathrm{p}=0.003$ ) years of age (Table 3, Fig. 4). Comparing the groups according to age and sex, the rate of awareness was lowest among women 50-59 years of age in the island group. The level of awareness was also significantly lower in the island group among men 60-69 years of age $(\mathrm{p}=$ $0.007)$ and women $50-59$ years of age $(p=0.001)$ than in the corresponding mainland groups.

The responses to the questions pertaining to COPD given by the 276 subjects who stated that they were aware of COPD are presented in Table 4. According to the accuracy rate for each question, the mainland group exhibited higher accuracy than the island group for all but one (question 4-d) of the six questions. The response and accuracy rates for the questions varied, with both being lower for the two questions relating to COPD as a leading cause of death (questions 4-d and 4-f).

\section{Discussion}

The main finding of this study was a low overall level of awareness of COPD of $21.3 \%$ in Matsuura, with rates of $24.5 \%$ and $11.8 \%$ in the mainland and island groups, respectively. In addition, the rate of COPD awareness among men and women was similar in the mainland group, whereas awareness was low among men in all age categories and varied widely among women in all age categories in the island group. We speculate that the main reason for the significantly higher rates of awareness is the mainland group is the fact that the subjects were amongst those who received the intervention aimed at raising awareness and early detection of COPD. It is unlikely that the difference in geo- 
Table 3. Rates of Awareness of COPD in Mainland and Island Groups according to Age and Sex

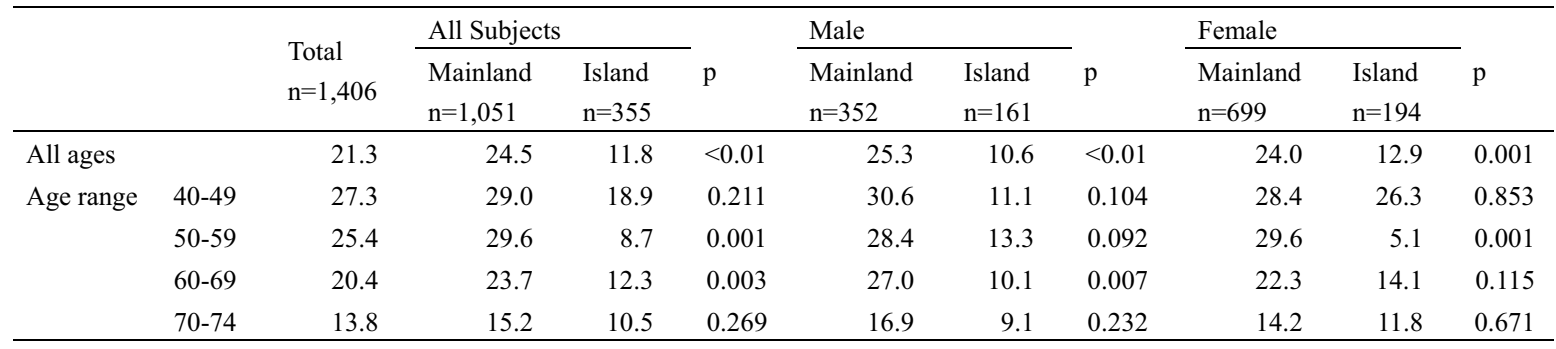

Data presented as percentages.

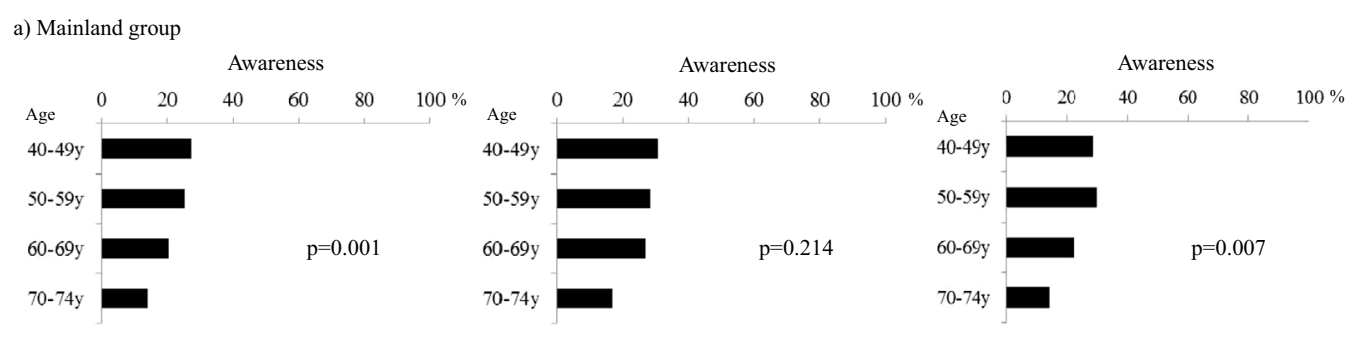

a-1) All subjects $(\mathrm{n}=1,051) \quad$ a-2) Male $(\mathrm{n}=352) \quad$ a-3) Female $(\mathrm{n}=699)$

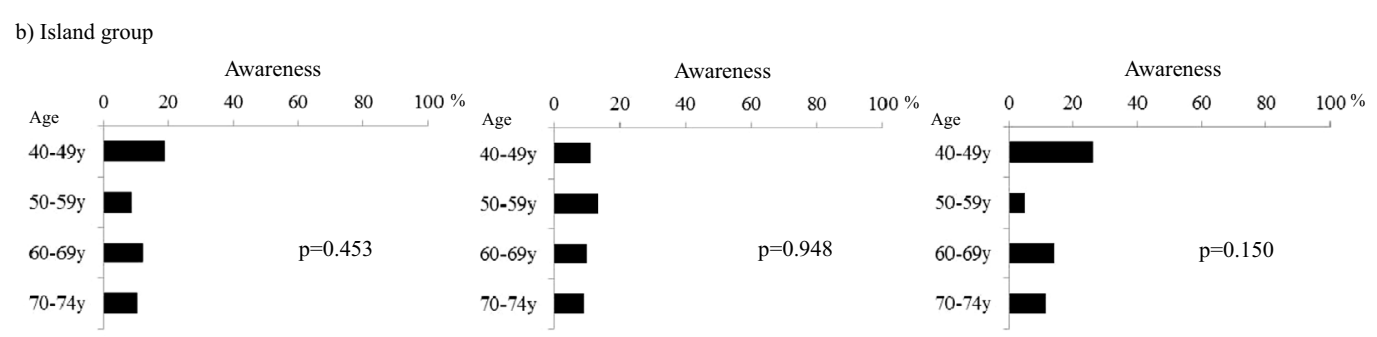

b-1) All subjects ( $\mathrm{n}=355) \quad$ b-2) Male $\quad(\mathrm{n}=161) \quad$ b-3) Female $(\mathrm{n}=194)$

$P$ value compares the difference of awareness among forties, fifties, sixties, and 70-74 years each group.

$40-49$ y: between 40 years old to 49 years old, 50-59y: between 50 years old to 59 years old, $60-69$ y: between 60 years old to 69 years old, 70-74y: 70 years old to 74 years old

Figure 4. Comparison of the rate of awareness of COPD according to age and sex between the mainland and island groups.

graphical location between the groups was a major factor contributing to the difference in awareness rates, as both groups had the same governance and medical and administrative services. COPD awareness in the island group among was lower women 50-59 years of age than in older women 60-74 years of age. However, we were unable to elucidate the reasons for the reduced awareness among those 50-59 years of age in this study.

Several studies of COPD awareness have been conducted in Japan. The Japan GOLD Committee carried out an online questionnaire survey among 10,000 people with 2,000 individuals in each decade of life from 20 to 60 years of age or older (16). The proportion of respondents with knowledge of COPD or who heard the term 'COPD' was $9.1 \%$ and $21.4 \%$, respectively (16). In another Japanese study of 335 subjects 18 years of age or older who had visited a community hospital, the proportion of respondents with knowledge about COPD or who heard the term 'COPD' was 9.3\% and $17.6 \%$, respectively (14). Compared with previous studies carried out in Japan, the rate of awareness in our subject cohort is low. This finding may in part be attributed to the older age distribution observed in our study. There is evidence that the rate of awareness of COPD is lower among older individuals (16), consistent with our study findings.

Smoking is a known risk factor for cancer and heart disease. However, the rate of awareness of the risk of myocardial infarction and cancer among smokers is only $29 \%$ and $40 \%$, respectively (18). Furthermore, there are reports that smokers, the elderly and individuals with lower levels of education have lower rates of awareness of the risks of these diseases $(14,18)$. Therefore, providing information about the increased risk of COPD associated with passive smoking is important for raising COPD awareness (19), and it is necessary to apply such interventions in all individuals 40 years of age or older and both smokers and non-smokers. However, the number of participants in the health classes, smoking cessation classes and public lectures for citizens was small in the present study. Hence, it is desirable to offer in- 
Table 4. Response Rate and Accuracy Rate for Responses to the COPD Knowledge Survey

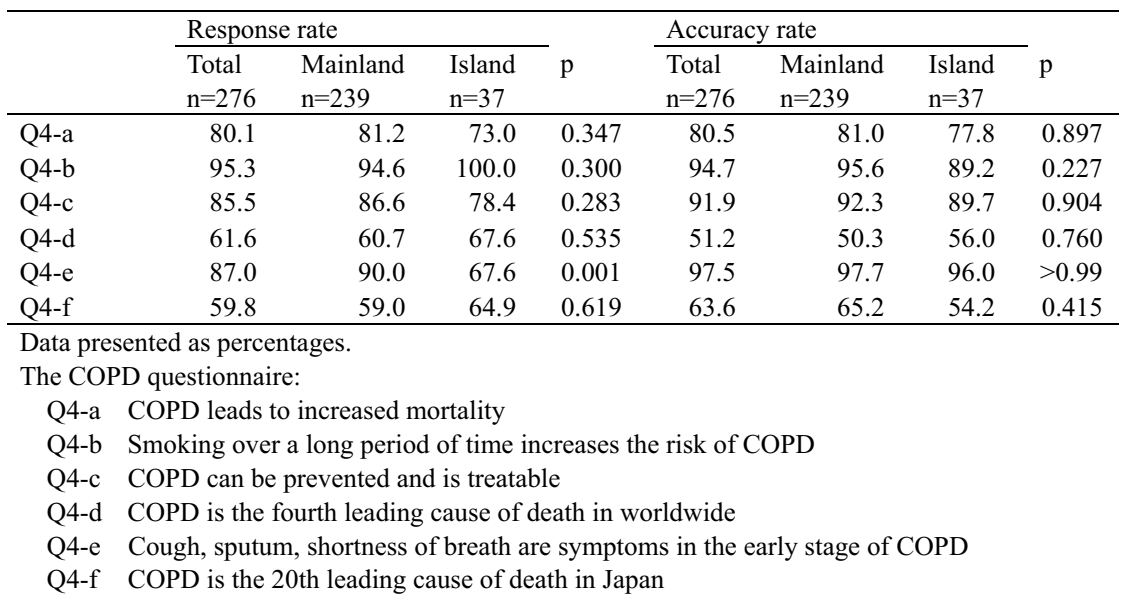

terventions in formats that enable residents to participate directly, such as COPD checkups, and enforce instructions for maintaining health and smoking cessation by providing such information in mass publications.

In the present study, the accuracy rate was high for questions related to the causes, symptoms and treatment of COPD among the subjects aware of COPD. This finding may be explained by the emphasis on information regarding the causes and symptoms of COPD given to those affected in Japan. The importance of improving awareness of the causes and symptoms of COPD is essential for early detection of the disease (14).

Many elderly people visit medical institutions due to lifestyle diseases and conditions related to aging. There are reports that COPD is frequently observed as a complication in patients who visit primary care facilities for the management of lifestyle diseases $(12,20,21)$. However, the diagnosis and treatment of COPD is currently not being implemented in such settings, as respiratory examinations are not generally performed at primary care facilities in Japan (22). Among efforts to raise awareness, it is also necessary to engage in strategies to promote early detection and treatment by providing instructions to healthcare professionals pertaining to respiratory examinations. Furthermore, it is necessary to implement educational activities that enable doctors, nurses and paramedics to stress that the risk of COPD increases with smoking and age and that COPD is a disease associated with many comorbidities (23).

One limitation of this study is the differences in the number of subjects in each group and the ratio of men to women. Specifically, the number of subjects in the island group who responded to the questionnaire was small, possibly related to differences in the local population of the two groups. In addition, the investigations of the level of awareness of COPD prior to the intervention and information related to smoking were insufficient. Therefore, we cannot conclude unequivocally that the intervention led to a change in awareness among the local residents.

\section{Conclusion}

In this study, we developed and implemented an intervention designed to promote the early recognition and treatment of COPD and found that the level of awareness in the mainland intervention group was higher than that in the island group. However, the rate of awareness remained low in both groups, and further strategies should be applied with the aim of improving awareness of COPD, especially among the elderly.

The authors state that they have no Conflict of Interest (COI).

\section{Acknowledgement}

We thank the study participants, staff of the government of Matsuura District, Nagasaki prefecture and coworkers for their help. In addition, we are grateful to Sue Jenkins, PhD, Associate Professor at the School of Physiotherapy and Exercise Science, Curtin University for her help in reviewing our manuscript.

\section{References}

1. National Heart Lung, and Blood Institute. Global Initiative for Chronic Obstructive Pulmonary Disease: Global strategy for the diagnosis, management, and prevention of chronic obstructive pulmonary disease. (REVISED 2011). 2011.

2. Jemal A, Ward E, Hao Y, Thun M. Trends in the leading causes of death in the United States, 1970-2002. JAMA 294: 1255-1259, 2005.

3. Ministry of Health Labour and Welfare. Vital Statistics. 2013 (in Japanese).

4. Mathers CD, Loncar D. Projections of global mortality and burden of disease from 2002 to 2030. PLoS Med 3: e442, 2006.

5. Ministry of Health Labour and Welfare. Patient survey. 2013 (in Japanese).

6. Fukuchi Y, Nishimura M, Ichinose M, et al. COPD in Japan: the Nippon COPD Epidemiology study. Respirology 9: 458-465, 2004.

7. Buist AS, McBurnie MA, Vollmer WM, et al. International variation in the prevalence of COPD (the BOLD Study): a population- 
based prevalence study. Lancet 370: 741-750, 2007.

8. Menezes AM, Perez-Padilla R, Jardim JR, et al. Chronic obstructive pulmonary disease in five Latin American cities (the PLATINO study): a prevalence study. Lancet 366: 1875-1881, 2005.

9. Lange P, Marott JL, Dahl M, Ingebrigtsen TS, Vestbo J, Nordestgaard BG. Substantial need for early diagnosis, rehabilitation and treatment of chronic obstructive pulmonary disease. Dan Med J 59: A4396, 2012.

10. Komase Y, Abe T, Kasahara K, et al. Survey on the handling of chronic obstructive pulmonary disease by annual health check in Japan. Intern Med 47: 1791-1796, 2008.

11. Kimura K, Kurosaki H, Wakabayashi R, et al. Concerns with the health check-up system for chronic obstructive pulmonary disease on two Japanese islands. Intern Med 50: 2135-2141, 2011.

12. Rennard S, Decramer M, Calverley PM, et al. Impact of COPD in North America and Europe in 2000: subjects' perspective of Confronting COPD International Survey. Eur Respir J 20: 799-805, 2002.

13. Kornmann O, Beeh KM, Beier J, et al. Newly diagnosed chronic obstructive pulmonary disease. Clinical features and distribution of the novel stages of the Global Initiative for Obstructive Lung Disease. Respiration 70: 67-75, 2003.

14. Uno T, Sato H. Survey to examine the need for awareness and dissemination of chronic obstructive pulmonary disease (COPD). Nihon Kokyuki Gakkai Zasshi (Annals of the Japanese Respira- tory Society) 2: 536-542, 2013 (in Japanese, Absrtact in English).

15. Kawakami M. Awareness of the harmful effects of smoking and views on smoking cessation intervention among Japanese medical students. Intern Med 39: 720-726, 2000.

16. The Japan GOLD Committee. Site of COPD [Internet]. [cited 2014 Feb 24]. Available from: http://www.gold-jac.jp/

17. Ministry of Health Labour and Welfare. Report of next national health campaign plan (Healthy Japan 21 2nd series). 2012 (in Japanese).

18. Ayanian JZ, Cleary PD. Perceived risks of heart disease and cancer among cigarette smokers. JAMA 281: 1019-1021, 1999.

19. Yin P, Jiang CQ, Cheng KK, et al. Passive smoking exposure and risk of COPD among adults in China: the Guangzhou Biobank Cohort Study. Lancet 370: 751-757, 2007.

20. Takahashi $T$, Ichinose $M$, Inoue $H$, Shirato $K$, Hattori $T$, Takishima T. Underdiagnosis and undertreatment of COPD in primary care settings. Respirology 8: 504-508, 2003.

21. Geijer RM, Sachs AP, Hoes AW, Salomé PL, Lammers JW, Verheij TJ. Prevalence of undetected persistent airflow obstruction in male smokers 40-65 years old. Fam Pract 22: 485-489, 2005.

22. Ryujin Y, Ogawa E, Seto R. Repeated educational campaigns about chronic obstructive pulmonary disease for general practitioners and their effectiveness. Respirology 18: 134, 2013.

23. Soriano JB, Visick GT, Muellerova H, Payvandi N, Hansell AL. Patterns of comorbidities in newly diagnosed COPD and asthma in primary care. Chest 128: 2099-2107, 2005.

(C) 2015 The Japanese Society of Internal Medicine http://www.naika.or.jp/imonline/index.html 